NISTIR 8229

\title{
Community Resilience Planning Guide for Buildings and Infrastructure Systems: Observations on Initial Implementations
}

\author{
Stephen A. Cauffman
}

This publication is available free of charge from: https://doi.org/10.6028/NIST.IR.8229

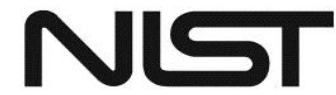

National Institute of Standards and Technology U.S. Department of Commerce 
NISTIR 8229

\title{
Community Resilience Planning Guide for Buildings and Infrastructure Systems: Observations on Initial Implementations
}

\author{
Stephen A. Cauffman \\ Materials and Structural Systems Division \\ Engineering Laboratory
}

This publication is available free of charge from:

https://doi.org/10.6028/NIST.IR.8229

September 2018

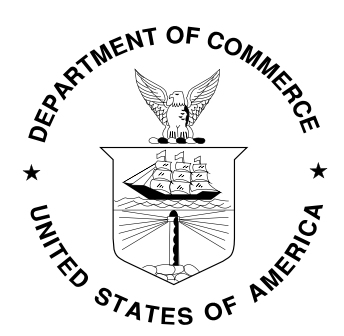

U.S. Department of Commerce

Wilbur L. Ross, Jr., Secretary

National Institute of Standards and Technology Walter G. Copan, NIST Director and Under Secretary of Commerce for Standards and Technology 


\title{
Foreword
}

This report was prepared under Interagency Agreement HSHQPM-15-T-00024 with the U.S. Department of Homeland Security Science and Technology Directorate, Standards Office.

\begin{abstract}
The National Institute of Standards and Technology (NIST) published the Community Resilience Planning Guide for Buildings and Infrastructure Systems (NIST SP 1190) in October 2015. The Guide describes a six-step process to develop a community resilience plan. The Guide was intended to be flexible, so that it could be used to create a standalone plan or to complement other planning processes by integrating resilience measures into longterm plans. Since the Guide's release, several communities have begun to use the Guide to develop resilience plans. This report documents three applications. The three applications, Fort Collins, Colorado, Delaware Department of Transportation, and Howard County, MD, offer three different approaches to the use of the Guide and demonstrate its flexibility.
\end{abstract}

\section{Key words}

Buildings; community; hazards infrastructure; planning; recovery; resilience. 


\section{Table of Contents}

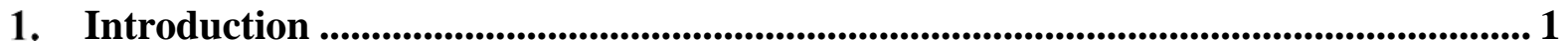

1.1. Background on the NIST Community Resilience Planning Guide and Economic

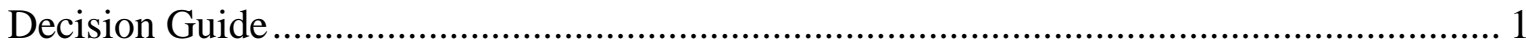

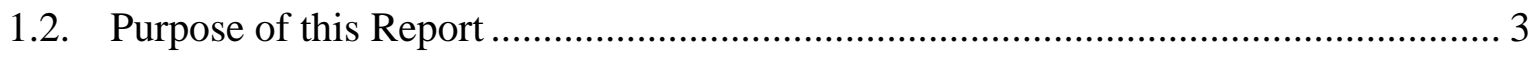

1.2.1. Locations and Hazards ............................................................................... 4

1.2.2. Community Characteristics ..................................................................... 4

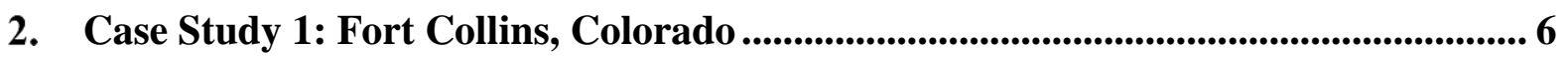

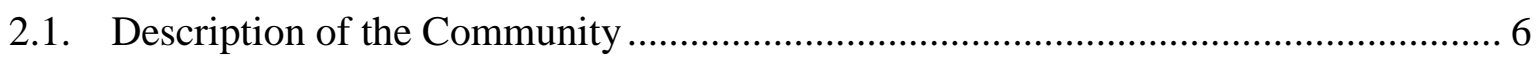

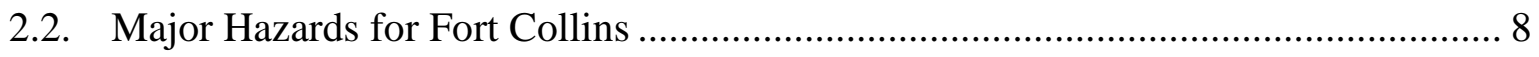

2.3. Current State of Planning in the Community .................................................. 9

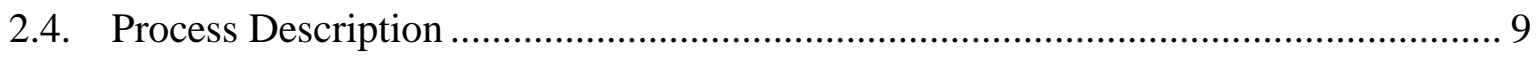

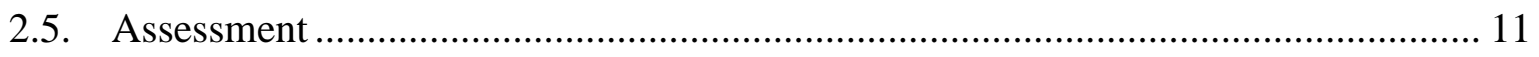

3. Case Study 2: Howard County, Maryland .......................................................... 14

3.1. Description of the Community ......................................................................... 14

3.2. Hazards for Howard County, Maryland .............................................................. 16

3.3. Current State of Planning in Community .......................................................... 16

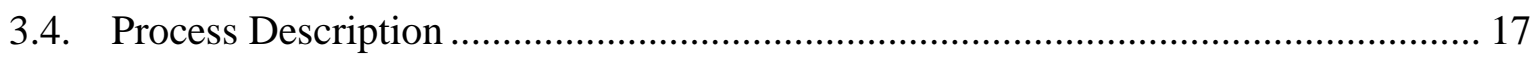

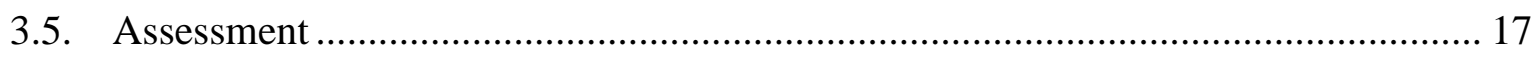

4. Case Study 3: Delaware Department of Transportation .......................................... 19

4.1. Description of the Community .......................................................................... 19

4.2. Major Hazards for State Route 1 .......................................................................... 20

4.3. Current State of Planning in Community ........................................................ 21

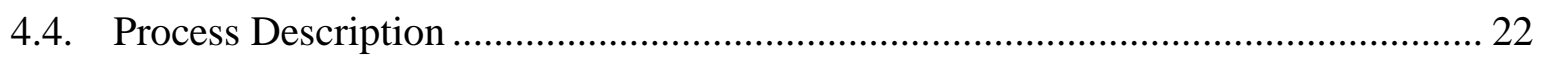

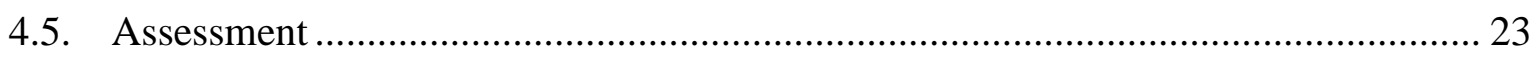

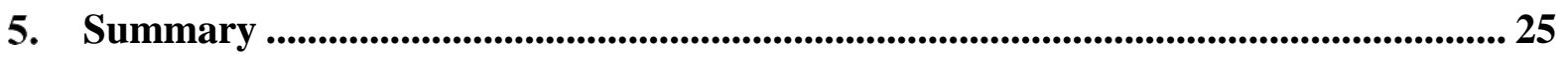

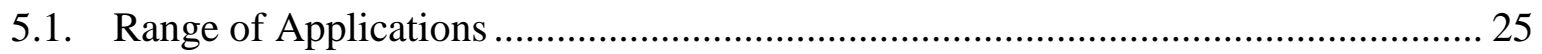

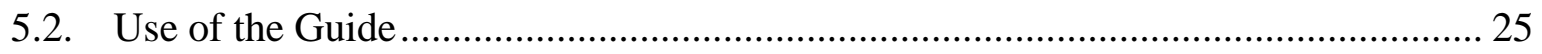

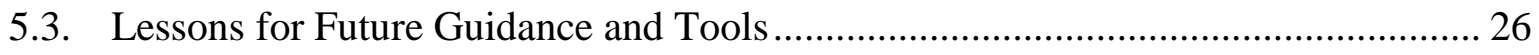

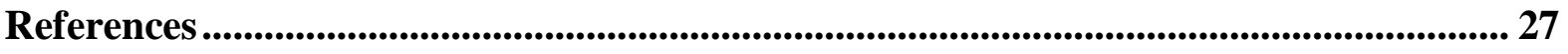

Appendix A: Sample Stakeholder Questionnaires........................................................... 29

Example Social Dimensions Task Worksheet \& Questions ......................................... 30

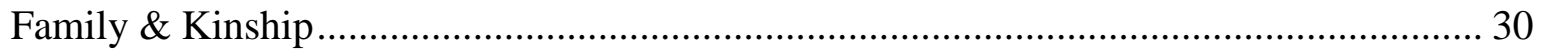




\section{List of Figures}

Figure 1-1: Community Resilience Planning Guide Six-Step Planning Process.................... 2

Figure 2-1: Map of Fort Collins, Colorado (@OpenStreetMaps contributors)....................... 7

Figure 3-1: Map of Howard County, MD. (COpenStreetMaps contributors) ....................... 15

Figure 3-2: Ellicott City, MD Historic District (COpenStreetMap contributors)................ 16

Figure 4-1: Delaware State Route 1 Corridor. (@OpenStreetMaps contributors)................ 21

\section{List of Tables}

Table 1-1: Summary of Communities Implementing the Guide ........................................... 4

Table 2-1: Population Breakdown of Fort Collins, Colorado by Race (Source: U.S. Census Bureau).

Table 2-2: Income and Poverty Data for Fort Collins, Colorado. (Source: U.S. Census Bureau).

Table 3-1: Population Breakdown of Howard County, Maryland by Race. (Source: U.S.

Census Bureau)

Table 3-2: Income and Poverty Data for Howard County, Maryland. (Source: U.S. Census

Bureau).

Table 4-1: Population Breakdown of Sussex County*, Delaware by Race. (Source: U.S.

Census Bureau)

Table 4-2: Income and Poverty Data for Sussex County*, Delaware. (Source: U.S. Census

Bureau). 


\section{Glossary}

CPT

DelDOT

DHS

EDG

Guide

NIST

RRAP
Collaborative Planning Team

Delaware Department of Transportation

U.S. Department of Homeland Security

Economic Decision Guide for Buildings and Infrastructure Systems

Community Resilience Planning Guide for Buildings and Infrastructure Systems

National Institute of Standards and Technology

DHS Regional Resilience Assessment Program 


\section{Introduction}

In October 2015, the National Institute of Standards and Technology (NIST) released the Community Resilience Planning Guide for Buildings and Infrastructure Systems (Guide) $(1,2)$. This was the first major deliverable under the NIST Community Resilience Program and an important document for guiding research under the Community Resilience Program. The Guide describes a six-step process for resilience planning that can be used to develop a standalone resilience plan for a community or to develop community resilience goals that are integrated into existing community plans. The Guide is being used by several communities around the United States and has received international attention and interest. The three implementations described in this report were sufficiently advanced that meaningful data about the effectiveness of the Guide, as well as any gaps or shortcomings, could be identified and documented.

This report provides an overview of the Guide, the locations where these implementations were conducted and how the guidance documents were used. It then provides a more detailed review of each project and what was learned about the process of using the guidance documents in each case. The results of this study are useful input to future guidance documents and provide insights for tools that facilitate their implementation.

\subsection{Background on the NIST Community Resilience Planning Guide and Economic Decision Guide}

The Guide focuses on the role of the built environment in supporting social and economic activities in a community, and how to improve community resilience by identifying goals for recovery of physical systems services and social and economic functions. One of the goals of the Guide development effort was to develop a process that could be applied to resilience planning given any hazard, whether natural, technological, or human-caused. The Guide process also had to be flexible such that it could be applied to communities of any size and accommodate differences in complexity.

NIST referred to two previous efforts as it began development of the Guide. The first was the Resilient City Study, undertaken by the San Francisco Bay Area Planning and Urban Research Association (SPUR) (3). The second was the Oregon Resilience Plan produced by the Oregon Seismic Safety Policy Advisory Commission (OSSPAC) (4). Both the SPUR study and the Oregon Resilience Plan focused on the built environment and its role in supporting response and recovery following a disruptive seismic event. The SPUR study focused on the impact and recovery within San Francisco following an earthquake that can reasonably be expected to occur once during the lifetime of a structure or system. For San Francisco, this corresponds to a magnitude 7.2 earthquake located on the peninsula segment of the San Andreas Fault. The Oregon Resilience Plan examined the impacts on the state from a Cascadia Subduction Zone earthquake and tsunami that would directly affect a relatively small part of the state but would have cascading consequences that would impact and disrupt social and economic activity throughout the state. Both studies linked the importance of developing and implementing resilience plans to ensure that when a disruptive event occurs, the affected areas can recover in a way that does not result in economic decline or loss of residents and businesses. 
These efforts considered resilience at a local (i.e., city) and state level. Other studies and guidance have considered resilience at a regional level since many infrastructure systems cross local boundaries and serve regional interests. NIST focused on the community scale (e.g., city, county) because at this level there is a governance structure and a defined geographic boundary. The Guide process is flexible and can be applied in other settings where these two conditions are met, such as a university campus or a military base. Local government is a logical convener, able to bring together relevant stakeholders at the local, regional, state, and federal level as needed for resilience planning. Finally, local government can either make decisions regarding resilience actions or influence decisions for assets and systems that are either municipally or investor-owned (e.g., utilities), privately owned, or owned and operated by state agencies (e.g., roads, bridges).

The six-step process is depicted in Figure 1-1. Step 1 describes the formation of the collaborative planning team, selecting a leader, and developing a stakeholder network to represent each of the social dimensions in the community. One of the key features of the Guide process is the explicit characterization of the social and economic dimensions of the community in Step 2. This allows the community to identify those dimensions that are critical to its initial response and longer-term recovery and to establish priorities. Understanding the social and economic priorities enables the community to map these priorities onto building clusters ${ }^{1}$ and establish resilience goals (expressed in terms of time to recover function) for the building clusters. The building clusters' dependency on infrastructure systems are also established. In Step 3, resilient performance goals for recovery of function (desired performance) are set independent of hazards. When the hazards are considered for determining anticipated performance of the built environment, gaps between the anticipated performance of a building cluster or infrastructure system and the desired performance represent opportunities to improve resilience. The process allows communities to identify areas where they may not have capacity to recover in the most resilient fashion following disruption and to consider alternatives to reduce vulnerabilities in Step 4.

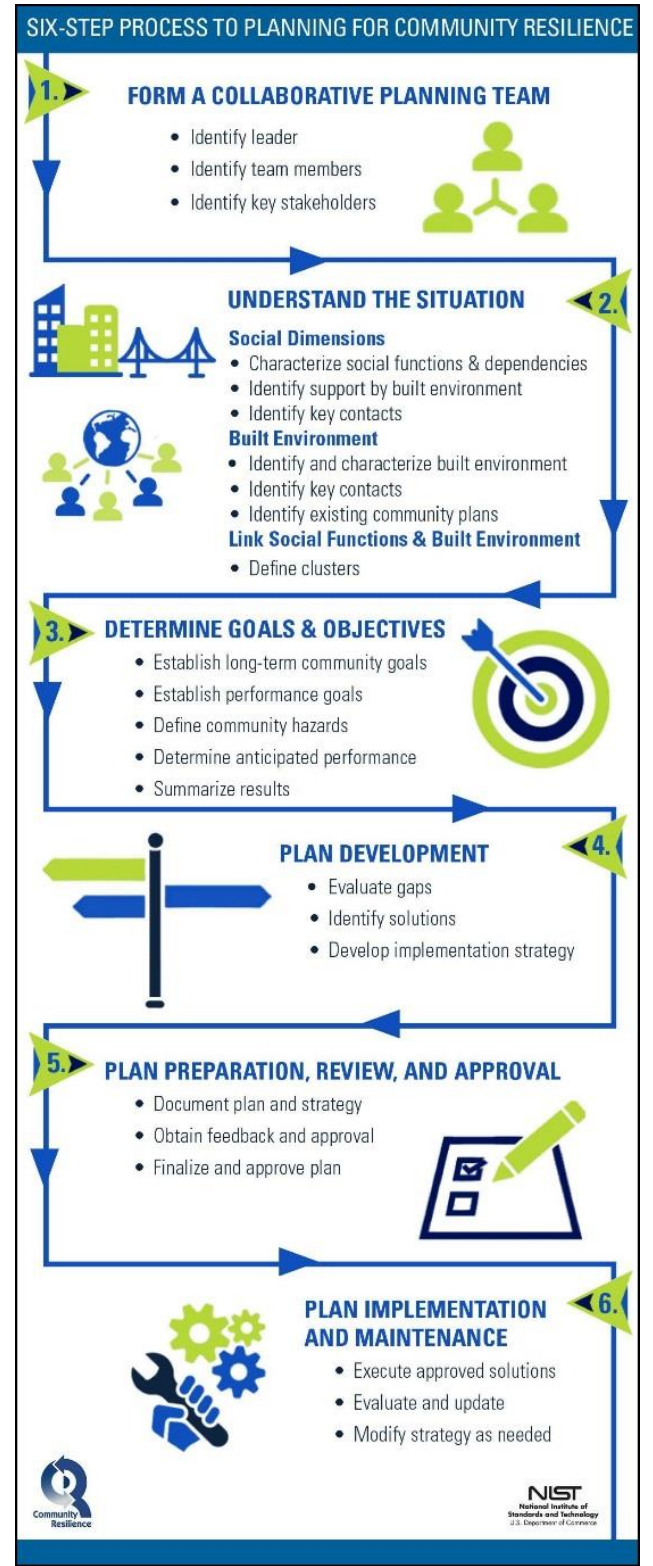

Figure 1-1: Community Resilience Planning Guide Six-Step Planning Process

\footnotetext{
${ }^{1}$ The term "building cluster" denotes a group of buildings serving a common function. Buildings within the cluster are not necessarily geographically co-located. Examples include residential housing, schools, or healthcare facilities. The clusters serve community social institutions and should have similar performance goals.
} 
Improvements could include administrative actions such as land use planning or buyback programs to reduce risk, mutual aid agreements to accelerate restoration of services, temporary measures to meet community needs following a hazard event, and construction or rehabilitation projects to improve the capacity of the built environment to withstand hazards. The Guide also considers the long-term plans of the community, so that resilience can be built over time and support community goals. The Guide can be used to create a standalone resilience plan or integrate resilience into existing community plans. The Guide is available on the NIST website at: https://www.nist.gov/topics/community-resilience/communityresilience-planning-guide.

\subsection{Purpose of this Report}

This report documents three uses of the Guide, specifically the approach that each user took to implement the Guide to meet their objectives. The report identifies practices or tools that were developed by these users that can be implemented by other users. The three implementations used the Guide in different ways. In Fort Collins, Colorado, the Guide process was implemented from Step 1 to Step 4 and the scope of the study addressed four social dimensions: Government, Education, Healthcare, and Community Service Organizations that provide shelter during emergencies. In Howard County, Maryland, the Guide was used as a resource to support the development of a recovery plan. Delaware Department of Transportation (DelDOT) used the Guide to support two highway corridor assessments and is also using the Guide as a reference in the development of the state's Strategic Implementation Plan for Climate Change, Sustainability, and Resilience for Transportation (23).

The Fort Collins example demonstrates how the Guide can be applied in a municipal setting. The resilience assessment focused on the City of Fort Collins, but since Fort Collins is the county seat for Larimer County, some county facilities located within the city limits were included in the assessment. Similarly, the Poudre School District serves several communities, including Fort Collins, so the function of the entire school district was considered.

Data for the Howard County use of the Guide was gathered through direct interaction with the Emergency Management staff authors of the Howard County Recovery Plan. Howard County contacted NIST in 2015 during the development of the Guide. Howard County was beginning work on a resilience plan and wanted to learn from NIST's work. In 2016, Howard County was in the process of developing a recovery plan for the county that used the NIST Guide as a reference. Following the flash flood in Ellicott City in July of 2016, NIST was invited to visit Ellicott City with the Office of Emergency Management staff of Howard County to discuss how the experience with the flood influenced the Recovery Plan.

The DelDOT project was centered around a highway corridor and its role in ensuring that the communities along the corridor can function and the extent to which function can be disrupted when the highway is not available. Like Fort Collins, data were obtained through direct interaction with the project lead on the highway corridor assessment. However, much of the project engagement with the local governments and key stakeholders took place without NIST involvement. NIST introduced the Guide process to local officials representing 
the cities along the State Route 1 corridor and met on several occasions with DelDOT staff and contractors involved in the assessment but NIST was not directly involved with broader stakeholder engagement.

\subsubsection{Locations and Hazards}

The Fort Collins, Colorado assessment focused on flood and wildland-urban interface fire as the principal hazards. The possibility of a train derailment leading to a hazardous chemical release was considered, since rail lines run through downtown and close to government facilities. A long-duration power outage was also considered since this was a DHS/FEMA priority during the assessment period.

Howard County, Maryland is a diverse county that contains highly urbanized areas and critical federal government facilities in the eastern part of the county and rural areas in the western part. Howard County has been very proactive in hazard assessment and mitigation, emergency operations planning, and more recently, recovery planning. The recovery plan was being developed, using the Guide as a reference, when a devastating flash flood struck Ellicott City on July 30, 2016. The County was able to test parts of the recovery plan in the wake of that event and gained valuable experience that informed the completion of the plan.

DelDOT used the Guide to support a highway corridor assessment. The State Route 1 corridor from Dewey Beach to Fenwick Island has four small cities along the corridor and the entire corridor is located within Suffolk County. The entire length of the corridor is at risk of flooding due to sea level rise and coastal storms. The purpose of the corridor assessment is to identify solutions to reduce the impact caused by frequent flooding.

\subsubsection{Community Characteristics}

Table 1-1 provides a summary of the characteristics of the three implementation locations discussed in this report. These locations represent application of the Guide at different scales (city, county, region).

Table 1-1: Summary of Communities Implementing the Guide

\begin{tabular}{|l|l|l|l|}
\hline \multicolumn{1}{|c|}{ Location } & \multicolumn{1}{|c|}{ Population } & \multicolumn{1}{c|}{$\begin{array}{c}\text { Governance } \\
\text { Structure }\end{array}$} & \multicolumn{1}{c|}{ Planning Focus } \\
\hline Fort Collins, CO & $\begin{array}{l}143,986(2010 \\
\text { Census })\end{array}$ & Council-Manager & $\begin{array}{l}\text { Flood; wildland- } \\
\text { urban interface fire; } \\
\text { hazardous chemical } \\
\text { release, long-term } \\
\text { power outage }\end{array}$ \\
\hline $\begin{array}{l}\text { Howard County, } \\
\text { MD }\end{array}$ & $\begin{array}{l}287,085(2010 \\
\text { Census })\end{array}$ & $\begin{array}{l}\text { County Council; } \\
\text { County Executive }\end{array}$ & Recovery plan \\
\hline
\end{tabular}




\begin{tabular}{|l|l|l|l|}
\hline Delaware State & Fenwick Island, DE: & All have council- & Coastal flooding \\
Route 1 & 379; South Bethany, & mayor governments & impacts on highways \\
& DE: 449; Bethany & & and communities \\
& Beach, DE: 1060; & & \\
& Dewey, DE: 341. & & \\
& Year-round & & \\
& residents. (2010 & & \\
& Census) & & \\
& & & \\
\hline
\end{tabular}




\section{Case Study 1: Fort Collins, Colorado}

\subsection{Description of the Community}

Fort Collins, Colorado (Figure 2-1) is located on the Cache La Poudre River along the Front Range of the Colorado Rocky Mountains, approximately 65 miles $(105 \mathrm{~km})$ north of Denver. The population, according to the 2010 census, was 143 986; the estimated population in 2016 was 164 207. Fort Collins has a diversified economy that includes higher education, technology, healthcare, retail, and manufacturing. The largest employer in Fort Collins is Colorado State University.

Table 2-1: Population Breakdown of Fort Collins, Colorado by Race (Source: U.S. Census Bureau)

\begin{tabular}{|l|l|}
\hline White alone, percent & $88.6 \%$ \\
\hline Black or African American alone, percent & $1.5 \%$ \\
\hline American Indian and Alaska Native alone, percent & $0.6 \%$ \\
\hline Asian alone, percent & $3.1 \%$ \\
\hline Native Hawaiian and Other Pacific Islander alone, percent & $0.1 \%$ \\
\hline Two or More Races, percent & $4.0 \%$ \\
\hline Hispanic or Latino, percent & $11.4 \%$ \\
\hline White alone, not Hispanic or Latino, percent & $80.8 \%$ \\
\hline
\end{tabular}

Table 2-2: Income and Poverty Data for Fort Collins, Colorado. (Source: U.S. Census Bureau).

\begin{tabular}{|l|l|}
\hline Median household income (in 2016 dollars) (2012-2016) & $\$ 57,831$ \\
\hline Per capita income in past 12 months (in 2016 dollars) 2012-2016) & $\$ 30,680$ \\
\hline Persons in poverty, percent & $17.8 \%$ \\
\hline
\end{tabular}




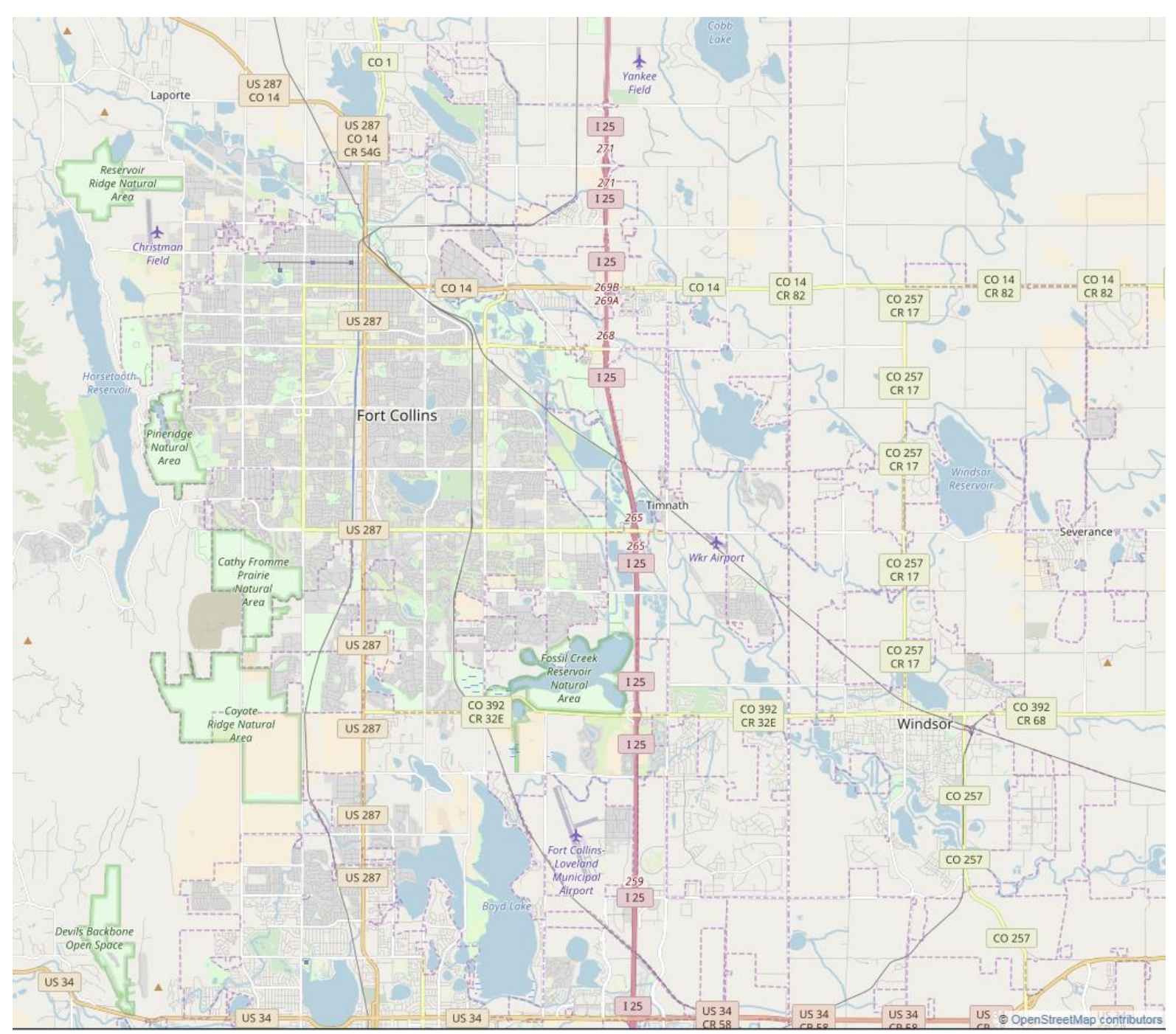

Figure 2-1: Map of Fort Collins, Colorado (COpenStreetMaps contributors).

Fort Collins has a council-manager form of city government. The mayor is elected to a twoyear term in elections held in odd numbered years. There are six city council members, each elected to four-year terms. Elections for the city council members are held every two years, staggered between even- and odd-numbered districts. The City Manager has overall responsibility for city operations and the council establishes policy direction. In addition to the City Government, Fort Collins is the county seat of Larimer County and houses county government facilities.

The information for this report was obtained through direct interaction with the users of the Guide. In Fort Collins, NIST participated in several on-site meetings of the collaborative planning team (CPT), accompanied the local lead (an emergency manager from Larimer County), Department of Homeland Security (DHS) Protective Security Advisor, and Idaho National Laboratory (INL) technical support staff on visits to key stakeholders in the city. The collaborative planning team was led by an emergency manager from Larimer County, working in coordination with the emergency manager from Fort Collins. Idaho National 
Laboratory provide technical analysis and support to the CPT. DHS also provided technical support to the CPT.

\subsection{Major Hazards for Fort Collins}

The City of Fort Collins and Larimer County have a long history of dealing with flash flooding. In 1864, a major flood on the Cache La Poudre River led to the relocation of Camp Collins from its original location near what is now Laporte to a new location near the historic downtown. The camp was renamed Fort Collins. In 1904, major flooding was experienced along the Poudre River due to heavy rains near Livermore. Other, lesser floods occurred through the years until another major flood on the Big Thompson River in 1976. In 1997, Fort Collins received 25-36 cm (10-14 in.) of rain during a 31-hour period, leading to five deaths and over $\$ 200$ million in damages. The campus of Colorado State University sustained over $\$ 140$ million in damages to buildings. The experience from this storm led the city to be proactive in removing structures from flood prone areas and to take steps to reduce the risk that flooding posed to the city, such as creating park areas that can flood during periods of heavy precipitation and channels to direct water to retention areas. The result is that during the September 9-16, 2013 rainfall event, little damage to structures occurred in Fort Collins despite up to $30 \mathrm{~cm}$ (12 in.) of rain.

While flooding is the hazard of greatest concern to the city, wildland-urban interface fires also pose a risk to the city. The High Park Fire in June of 2013 burned in Larimer County northwest of Fort Collins. This was the second largest wildfire in Colorado history based on the area burned $353 \mathrm{~km}^{2}$ (87 284 acres). The High Park Fire destroyed 259 buildings and there was one fatality, although Fort Collins was not directly affected. Wildfire scarring can also exacerbate flood risks since rainfall is not easily absorbed into the soil and quickly flows into streams.

Fort Collins can also experience tornadoes, although these are relatively rare along the front range of the Rocky Mountains. Since 1954, seven tornadoes have been recorded in Fort Collins, none more intense than EF 12. A 2008 tornado rated EF 3 struck Windsor, Colorado, just east of Fort Collins causing \$ 147 million in damages, one fatality, and 78 injuries. There were 850 homes damaged and approximately 300 either damaged or unable to be occupied along the path of the storm. Given the infrequent nature of the tornado hazard in Fort Collins, the hazard was not considered in detail for this study.

Fort Collins is also at risk of technological hazards. Three rail lines run either in downtown or within the city limits. Both BNSF and Union Pacific operate trains on tracks that pass

\footnotetext{
${ }^{2}$ The Enhance Fujita Scale is used to rate the intensity of tornadoes. Trained National Weather Service personnel use a series of damage indicators (buildings and other structures) to estimate the intensity of a tornado. The scale is shown in the table below:

\begin{tabular}{|c|l|}
\hline EF Rating & 3 -second Gust $\mathrm{km} / \mathrm{h}(\mathrm{mi} / \mathrm{h})$ \\
\hline 0 & $105-137(65-85)$ \\
\hline 1 & $138-177(86-110)$ \\
\hline 2 & $179-217(111-135)$ \\
\hline 3 & $219-266(136-165)$ \\
\hline 4 & $267-322(166-200)$ \\
\hline 5 & over 322 (over 200$)$ \\
\hline
\end{tabular}
}


through downtown Fort Collins. OmniTrax Great Western operates $129 \mathrm{~km}$ (80 miles) of track along the front range and provides interchange services with the Union Pacific and BNSF railroads. Some of the Great Western track is located within the city limits of Fort Collins. Given the rail traffic through the city, a scenario of a train derailment resulting in the release of a chemical inhalation hazard was considered as a possible hazard.

The third hazard scenario considered was a long-term power outage. This was included in the study since long-term power outage and the resulting consequences were a priority for FEMA during the assessment period.

\subsection{Current State of Planning in the Community}

The City of Fort Collins has an active planning program. The city maintains a strategic plan (9), which is updated on a two-year cycle. Fort Collins maintains a City Plan (comprehensive plan) (10), which has a 20-year planning horizon. It also has plans for economic development, transportation, and other elements that align with the City Plan (11). The Northern Colorado Regional Hazard Mitigation Plan (12), which covers Fort Collins, Larimer County, City of Loveland, Town of Estes Park, Town of Wellington, and the Town of Berthoud was updated in 2013. Several continuity of operation plans were also reviewed and were important to help the team establish resilience performance goals for the building clusters and infrastructure sectors of interest. These plans included the following:

- The City of Fort Collins Continuity of Operations Plan

- The Larimer County Continuity of Operations Plan

- The Larimer County Sheriff's Office Continuity of Operations Plan

In addition to the city and regional plans, the State of Colorado developed the Colorado Resilience Framework (6). The Colorado Resilience Framework was published in 2015, following the 2013 floods that severely impacted Boulder County. The Framework is intended to look holistically at the shocks and chronic stresses faced by the state, identify problems and set strategies and goals for addressing those problems. It also establishes the role of the state and communities in building resilience.

\subsection{Process Description}

The City of Fort Collins was proposed by the DHS Protective Security Advisor for Colorado for the Regional Resilience Assessment Program (RRAP) and the city was selected by the RRAP program for a start in 2016. The DHS RRAP team made the decision to use the Community Resilience Planning Guide at the during the 2016 RRAP kickoff meeting in 2015. Since this was the first application of the Guide to a resilience assessment, there was a learning curve associated with the application of the process in Fort Collins. For example, engagement of stakeholders took longer than expected due to the need to make a compelling case for why resilience planning was important for their operations. Also, considering multiple dependency paths between systems rather than for single infrastructure systems led INL to develop tools to support the analysis. Further, since the project was being conducted 
as a DHS Regional Resilience Assessment, the Guide process was modified somewhat to both meet the objectives of the RRAP while at the same time provide recommendations for resilience improvements to the city's infrastructure.

Step 1. The first step in the Guide process is the formation of the Collaborative Planning Team (CPT). The team was led by an Emergency Management Coordinator from Larimer County and supported by the Emergency Management Director from Fort Collins. The CPT was composed of representatives from the following:

- Larimer County Emergency Management

- Fort Collins Emergency Management

- Fort Collins Department of Planning, Development, and Transportation

- Fort Collins Utilities - Water and Power \& Light

- Fort Collins Office of Social Sustainability

The CPT held an initial meeting to introduce the Guide process and the plans for the resilience assessment. The CPT leader developed an outreach plan to work with stakeholder groups to foster their support for the effort and to collect data that would be important to Steps 2 and 3 of the Guide process. These stakeholder interactions allowed the CPT to identify additional members who would support the process to completion. (Appendix A provides an example of questions asked of stakeholder groups).

Step 2. Step 2 of the Guide process, Understanding the Situation, is intended to develop an understanding of the local values, goals, and priorities. It also identifies social and economic institutions of the community and their dependence on buildings and infrastructure to perform their intended functions, particularly in times of disruption due to hazards. The CPT identified 27 plans produced by the city that were reviewed to understand the city's longterm goals for development and inform the resilience planning process. ${ }^{3}$ The CPT also reviewed continuity of operations plans (listed in Section 2.3) to understand the desired performance for these facilities in an emergency.

Step 2 involves identification of the building stock and the infrastructure systems that support the operation and functionality of buildings. This part of the task was accomplished using open source documentation as well as information gathered from meetings with stakeholder groups. The INL team used this information to map dependencies using an automated tool developed by the Laboratory. The dependency maps developed for the project allowed the team to identify the possible cascading consequences of failures and their impact on resilience of the city and supported recommendations to address gaps that could lead to improved performance. The team used the dependency maps as a basis for follow-up meetings with stakeholders to refine their dependency assessments and verify that the dependency maps accurately reflected conditions.

Step 3. As the assessment entered Step 3 of the Guide process, the collaborative planning team worked with stakeholders in the four functions (government, healthcare, education, and

\footnotetext{
${ }^{3}$ Adopted Fort Collins plans are available online at: https://www.fcgov.com/planning/documents.php. Note that not all plans developed by the city were reviewed as part of the RRAP. Only those plans that were most relevant for resilience planning were reviewed.
} 
service organizations providing emergency shelter) and with the utility providers to define performance objectives for buildings and infrastructure.

The RRAP team evaluated flooding and wildland-urban interface fire as the primary hazards of concern, based on a review of the Larimer County Hazard Mitigation Plan. The team also considered a train derailment and hazmat release on the BNSF rail line that runs through the city and a long-term power outage. The team developed performance goals tables based on the approach described in the Community Resilience Planning Guide and tailored the performance goal tables to reflect the functional requirements and dependencies for the four community functions of interest. The INL team supported this effort and the analysis to determine anticipated performance by developing detailed dependency maps. These maps allowed the team to evaluate system level response and identify areas where there were gaps that if addressed could lead to improved performance.

Step 4. The Fort Collins assessment ended at Step 4 of the Guide process, in which the identified performance gaps are evaluated, prioritized, and solutions determined that can be part of an implementation strategy. The team provided the city with a set of options to improve resilience. Since Fort Collins is active in planning, these options were presented such that they can be incorporated into other plans for implementation. The RRAP team also provided the city with a dependency mapping tool, implemented in ArcGIS, that will allow the city to consider dependencies when considering future projects. The tool has currently been delivered only to DHS and the City of Fort Collins.

\subsection{Assessment}

The Fort Collins use of the Guide process was tailored to address the requirements of the Regional Resilience Assessment Program, focusing on the role of infrastructure and critical buildings in the four social dimensions: governance, education, health and community serving organizations providing sheltering services. The experience in Fort Collins provided useful insights as to how the process works and opportunities to provide additional guidance that would be helpful to future users. The following observations were obtained from working with the collaborative planning team and stakeholders.

Step 1: Form a Collaborative Planning Team

The collaborative planning team should consist of local representatives who understand and accept the value of community resilience planning, are committed to the process, and are able to champion resilience and engage the relevant stakeholders. Resilience planning is inherently a local issue and must reflect local customs, priorities, practices and capabilities. Even though this implementation was initiated under a DHS-led national program, committed local leadership was an essential element of its success.

Resilience planning requires the engagement of the collaborative planning team and a larger group of stakeholders, it is important to socialize the resilience planning concept ahead of time to build support and understanding ahead of initiating the planning effort. Since this effort started before stakeholder buy-in had been received, there was some initial hesitance 
by stakeholders to engage in the project. While this hesitance was overcome, it did require additional time early in the project to work with stakeholder groups and ensure their engagement and support of the effort.

Endorsement by elected leadership is essential. Elected leadership is able to communicate the goals and objectives of the resilience planning effort to community members, businesses, and other stakeholders and encourage their support and participation in the planning effort and eventual implementation. Further, elected leadership can act on recommendations or influence actions that lead to greater resilience.

In some cases, external organizations may perform resilience assessments on behalf of the local government. In the case of Fort Collins, the INL team conducted the resilience assessment. Where external organizations are performing analyses and informing the collaborative planning team, it is important for the collaborative planning team to receive periodic updates on the analysis. These updates are important not only for keeping the collaborative planning team and stakeholders informed of progress and findings but also for confirming the analysis organizations' understanding of the buildings and infrastructure dependency relationships. Regular interaction can lead to better analysis outcomes and ultimately a well-informed resilience plan. In Fort Collins, regular meetings between the collaborative planning team and stakeholder groups allowed for dependency models to be refined based on experience and stakeholder understanding of systems.

Step 2: Understand the Situation

As soon as possible after the start of the project, it is important to identify the lifeline service providers and contacts for the region. If there is not an established cooperative arrangement in place, the CPT should work with the service providers to address concerns about information exchange and security. To the extent possible, sensitive infrastructure information should remain with the owner and the information exchange limited to what is needed to establish goals and priorities, determine anticipated performance, and agree on possible solutions to meet resilience goals.

For each of the social functions identified in the Community Resilience Planning Guide, a point of contact should be identified who can assist the CPT with detailed understanding of that function and the associated local attributes and dependencies. The Fort Collins CPT developed a relatively short questionnaire that facilitated information collection about recovery time objectives, dependencies, and existing practices for continuity of service and allowed the CPT to have more focused discussions with stakeholders to better inform the study. The team also found it helpful to develop a simple spreadsheet that included all the functional categories within each social function (e.g., the government function would include emergency services, information technology, emergency communications, public safety, judicial, criminal justice, municipally-owned utilities, transportation services/traffic management, and governance). This helped the stakeholder groups identify buildings and infrastructure that were required for the specific social function to provide services to the community and to identify contacts and plans that would be relevant to the resilience planning process. 
Step 3: Determine Goals and Objectives

In a city such as Fort Collins that does short-term, long-term, and strategic planning, there is a wealth of existing data and information that can be used to determine priorities for building and infrastructure performance, based on the culture, history, plans for future development, growth, and adaptation. Plans such as the hazard mitigation plan, master plan, and capital improvement plans are also the logical vehicles for implementation of resilience projects and for alignment of such projects with other community goals. The assessment included a review of 27 separate plans, which helped the team understand the city's priorities, plans for development, and assess preparedness, particularly for critical facilities and infrastructure. However, the review did not include a comparison of policies to identify conflicts or opportunities to integrate planning to include resilience. An opportunity exists to provide additional guidance on a uniform method for review and integration of resilience goals with local and regional plans. For example, the hazard mitigation plan and any hazard or risk assessments are useful for defining the hazards of concern that should be included in the resilience approach.

Local GIS resources can be especially helpful to resilience planning efforts. These resources may include data on the location of buildings (by type or function), location of infrastructure systems and assets, and hazard data. Local GIS personnel can assist the planning team to understand and interpret data. Engaging these resources early in the resilience process facilitates the resilience analysis process by providing detailed information on buildings and infrastructure assets, geographic location (which can affect vulnerability), and dependency relationships.

INL used a dependency mapping tool, called the All-Hazards Knowledge Framework (AHA) to identify the dependencies among buildings, infrastructure, and social systems. The results of this analysis provided a visual depiction of the dependencies and the consequences of failure that allowed stakeholders to see and understand how these dependencies could affect their ability to deliver services following hazard events. This experience points to the need for validated tools to evaluate the resilience of a community as a system, assess the impact of failures (or loss of capacity) and identify and evaluate possible solutions. Map-based, visual tools will be especially important to meeting this need.

\section{Step 4: Plan Development}

Prioritized actions were proposed such that they can be incorporated into existing city planning processes for implementation. The CPT used the performance goals tables to identify gaps in performance and develop an implementation strategy. The gaps and their potential to disrupt critical community functions were documented along with proposed actions to improve performance and enhance resilience. As noted previously, INL also delivered a dependency analysis tool to Fort Collins and DHS. The tool can be used by the city to consider dependencies when planning infrastructure projects. 


\section{Case Study 2: Howard County, Maryland}

\subsection{Description of the Community}

Howard County, Maryland is a large, diverse county located south and west of the city of Baltimore. The eastern part of the county is suburban and heavily developed, while the western part of the county is more rural. The county has a population of 287085 according to the 2010 census and covers an area of $655 \mathrm{~km}^{2}\left(253 \mathrm{mi}^{2}\right)$. The county seat is Ellicott City, with a population of 65834 as of the 2010 census and having an area of $77.9 \mathrm{~km}^{2}\left(30.1 \mathrm{mi}^{2}\right)$. The county is governed by a county council, comprising elected representatives from the five districts in the county and an elected county executive.

Table 3-1: Population Breakdown of Howard County, Maryland by Race. (Source: U.S. Census Bureau)

\begin{tabular}{|l|l|}
\hline White alone, percent & $57.3 \%$ \\
\hline Black or African American alone, percent & $19.5 \%$ \\
\hline American Indian and Alaska Native alone, percent & $0.4 \%$ \\
\hline Asian alone, percent & $18.9 \%$ \\
\hline Native Hawaiian and Other Pacific Islander alone, percent & $0.1 \%$ \\
\hline Two or More Races, percent & $3.7 \%$ \\
\hline Hispanic or Latino, percent & $6.8 \%$ \\
\hline White alone, not Hispanic or Latino, percent & $52.1 \%$ \\
\hline
\end{tabular}

Table 3-2: Income and Poverty Data for Howard County, Maryland. (Source: U.S. Census Bureau)

\begin{tabular}{|l|l|}
\hline Median household income (in 2016 dollars) (2012-2016) & $\$ 113800$ \\
\hline Per capita income in past 12 months (in 2016 dollars) 2012-2016) & $\$ 49667$ \\
\hline Persons in poverty, percent & $5.2 \%$ \\
\hline
\end{tabular}




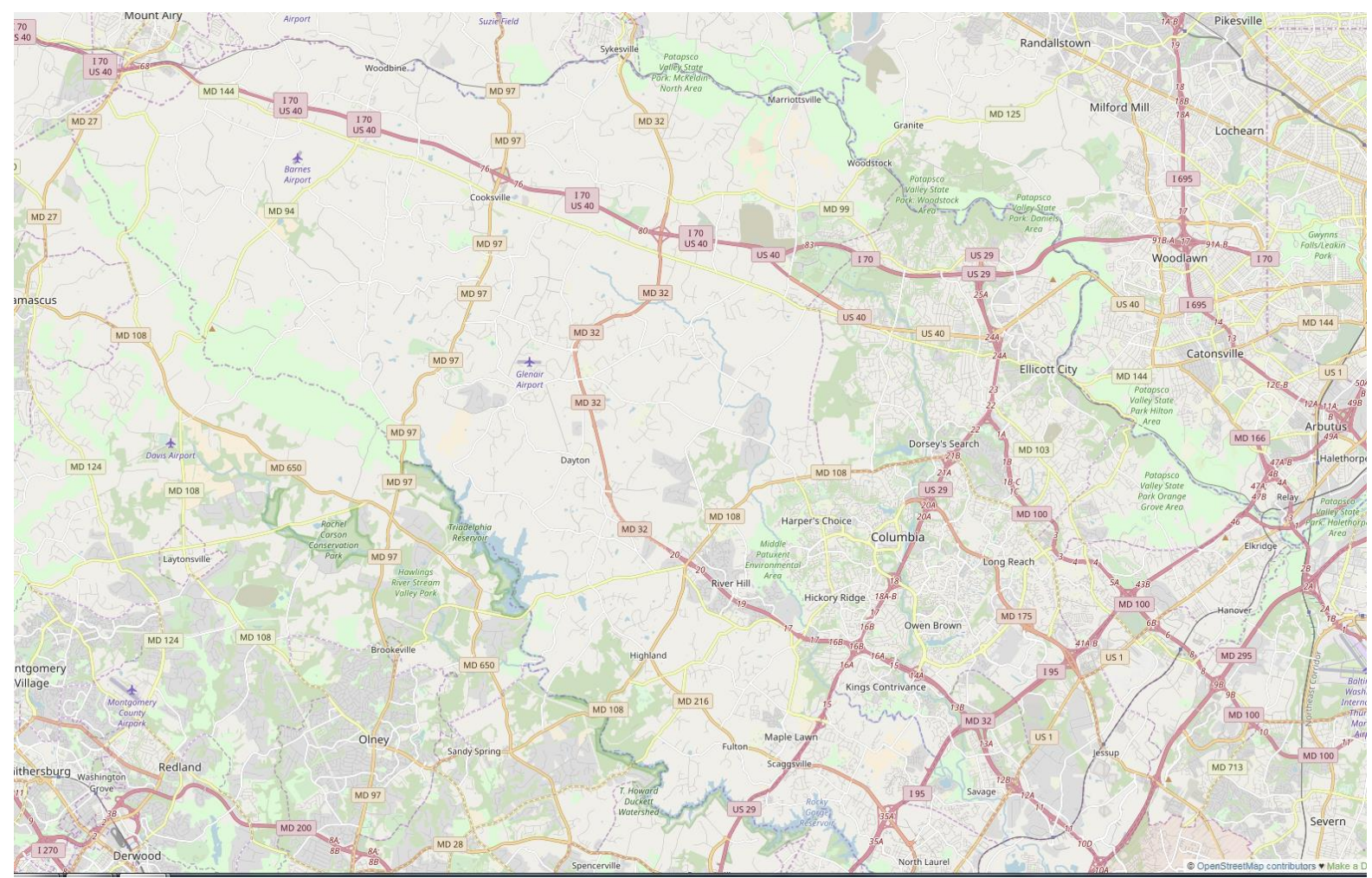

Figure 3-1: Map of Howard County, MD. (@OpenStreetMaps contributors)

This case study focused on Ellicott City. When the city was founded, it was built along a fall line where water could be used to power mills. The historic district of Ellicott City is susceptible to flooding, either from the Patapsco River that runs along the eastern end of the historic district or from the streams that flow into and through the historic district. In 2016, a thunderstorm that produced $15 \mathrm{~cm}$ ( $6 \mathrm{in}$.) of rain in approximately 2 hours, caused the streams to overflow their banks, and the resulting flash flood significantly damaged buildings and infrastructure on Main Street. The County's Emergency Management Office was developing a recovery plan at the time of the flood and while the plan had not been completed, the County had the opportunity to test the recovery plan and use the experience to further refine the plan. The Guide was one of several resources the County had used to develop its recovery plan and thus provided an opportunity to derive lessons that could further advance resilience planning. 


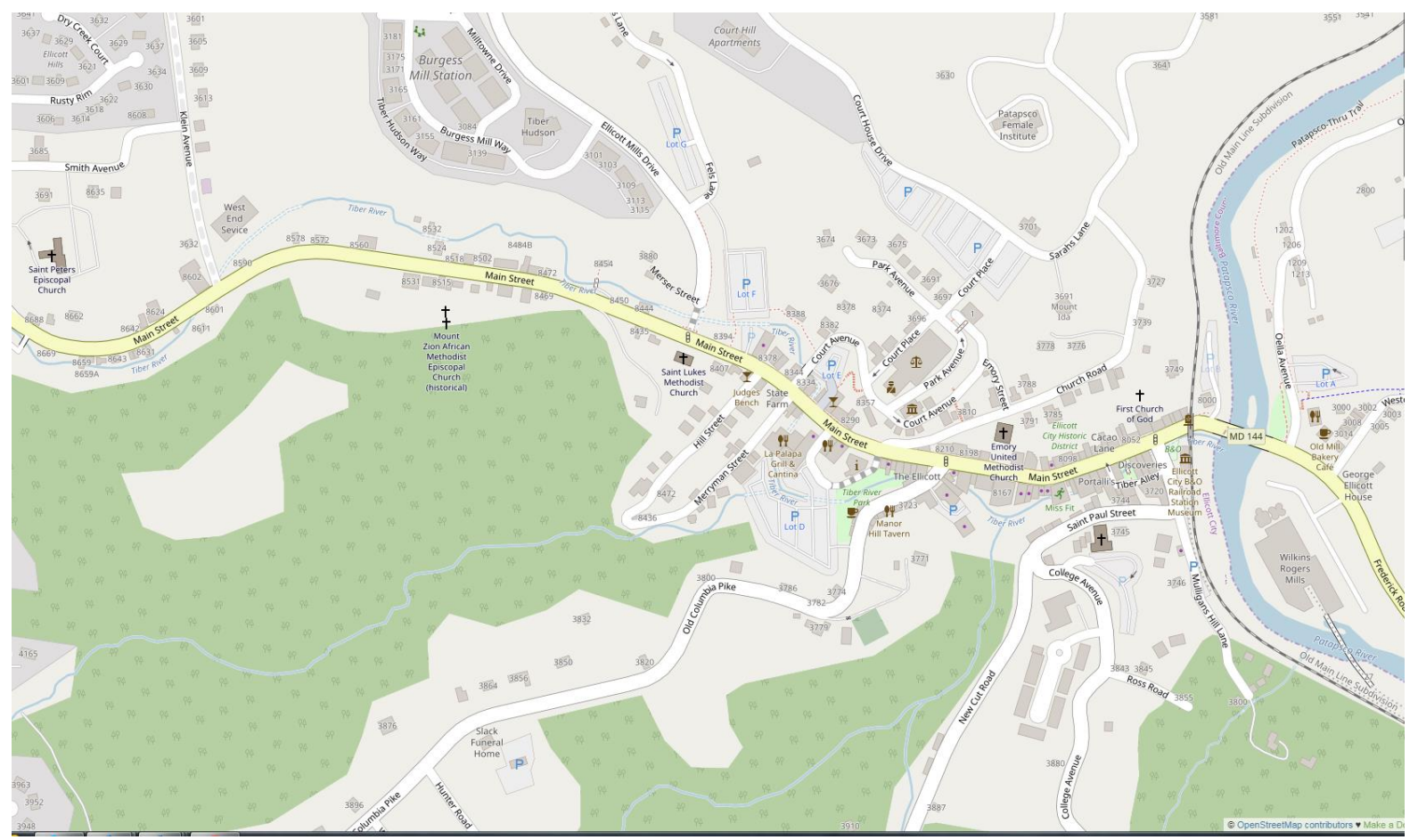

Figure 3-2: Ellicott City, MD Historic District (@OpenStreetMap contributors).

\subsection{Hazards for Howard County, Maryland}

Howard County has conducted several hazard assessments and has identified significant hazards, characterized their likelihood and consequence, and communicated this information to the public as a part of preparedness efforts. Given the importance of Ellicott City to Howard County, both as the seat of county government and the significance of the historic downtown area to the county economy, this section focuses on resilience planning by Howard County for Ellicott City.

Given its location, the historic district is prone to flooding, both from the Patapsco River immediately east of the historic district and the Tiber River that flows through the historic district, passing under Main Street and several buildings. The city suffered a significant flash flood event in July 2016, that damaged many buildings and caused damage to streets, sidewalks, and other infrastructure. Two people died during the 2016 flash flood.

\subsection{Current State of Planning in Community}

Howard County maintains a proactive planning process. The county released Plan Howard 2030 in July of 2012 and amended the plan in February 2018 (16). In addition, the county maintains up-to-date plans for emergency management (17), and economic development (18), as well as detailed plans to implement the goals of the master plan (19). The hazard mitigation plan is developed and maintained by the State of Maryland and was updated in 2016. At the time of the 2016 flood, the county was in the process of preparing a recovery plan. 


\subsection{Process Description}

Howard County was developing a recovery plan at the time the 2016 flood struck Ellicott City. The County used the Guide to inform the development process. The 2016 flood occurred during the recovery plan development and gave the County an opportunity to test the recovery plan and work toward building resilience as a part of the recovery process. While Howard County's approach to recovery did not follow the Guide process step-by-step, it is possible to identify steps the county took that are consistent with the Guide process and to derive lessons that support the Guide process or identify areas where additional guidance would be useful. Unlike the Fort Collins and DelDOT projects, Howard County was recovering from the 2016 flash flood disaster, which provided a different perspective on planning.

Step 1. Howard County did not formally establish a CPT. As the County transitioned from response to recovery, the need for a dedicated recovery manager was recognized and staffed. The recovery manager effectively functioned as the CPT lead. Representatives from the Emergency Operations Department, which was responsible for leading the recovery plan development, the County's Office of Economic Development, Office of Planning and Zoning, and the Deputy City Administrator for Ellicott City participated in planning and implementing actions to help the historic district of Ellicott City recover quickly.

Step 2: Following the flood, Howard County assessed the conditions of buildings and infrastructure within the historic district affected by the flash flood. Maintaining the historic fabric was an overarching consideration of the recovery. Because the historic district was a significant economic contributor in the County, it was important to retain as many businesses as possible and to help them reopen. These considerations were central to the planning and implementation of actions to improve resilience during recovery.

Step 3: Howard County undertook their own process for developing a recovery plan and the Guide served as a useful reference. During the recovery, the County identified some priorities, such as improving underground utilities and moving some electric distribution lines underground to improve resilience to future hazards.

\subsection{Assessment}

Howard County was developing its recovery plan before the 2016 flood in Ellicott City. The flash flood presented an opportunity to implement the plan and to learn from the experience. The response and recovery to the flood have identified several points that are relevant not only for post-disaster recovery, but also for planning to reduce risk in future events. The following points made by Howard County Emergency Management and County Government staff are organized by the steps in the Guide.

Step 1: Form a Collaborative Planning Team 
An integrated planning approach for recovery was important. Even before the 2016 flood, Howard County recognized the importance of bringing together stakeholders within the county government and from outside to inform their planning. In addition to the Emergency Operations Department, which was responsible for leading the recovery plan development, the team included participation from the County's Office of Economic Development, Office of Planning and Zoning, and the Deputy City Administrator for Ellicott City.

A dedicated recovery manager needs to be identified, whose sole responsibility was to work with all the necessary organizations to ensure that recovery proceeded. In Howard County, recovery manager coordinated all the stakeholders working to help the city recover from the floods and worked with the Office of Emergency Management and other county officials to ensure that all efforts were aligned to make the recovery as efficient as possible. The recovery manager operated as a CPT lead working with all of the stakeholders and balancing interests during recovery.

Step 2: Understand the Situation

Historic communities value maintaining the historic character of the built environment, while working to improve resilience. The 2016 flood affected a relatively small part of the city; however, this affected area is the historic heart of Ellicott City and a significant economic engine for the County (21). So, there was a desire to restore the historic district as much as possible to its pre-flood condition as well as to assist residents and business owners with their recovery. As the historic district began its recovery, the County, businesses and homeowners, utilities and other stakeholders worked to maintain the historic fabric of the area while incorporating changes that would improve resilience to future floods.

Resilience planning requires coordination of all planning documents. The county noted that their plans (i.e., Master Plan, Hazard Mitigation Plan, Economic Development Plan, etc.) have historically been isolated from each other. One change that has resulted from the 2016 flood is that county has now integrated their planning processes so that everything flows into the county master plan. The master plan contains priority projects that meet county objectives and include measures to enhance resilience to future hazard events. As part of the effort to harmonize planning processes, the county has also seen the value of linking planning and zoning to ensure that land use and development plans are consistent with the hazards present.

Step 3: Determine Goals and Objectives

The County identified gaps and planned actions that were consistent with the historic fabric of the affected area while improving resilience to future hazards. Howard County developed a recovery plan using the Guide as a reference. The County was able to implement many of the concepts contained in the Guide. Exercising the recovery plan following the 2016 Ellicott City Flood either confirmed or identified practices that enabled the County to recover rapidly and to incorporate measures that improve resilience. The result was that two years after that flood, most of the businesses in the historic district had reopened. Further, the County had 
taken concrete steps to integrate resilience into the County's master plan, which provides an implementation vehicle and time-phased means to build resilience over time.

\section{Case Study 3: Delaware Department of Transportation}

\subsection{Description of the Community}

The Delaware Department of Transportation (DelDOT) had a highway corridor assessment planned as a part of their normal operations and used the Guide to support their resilience studies. DelDOT evaluated the impact of road closures due increased frequency of flooding and to assist in identifying projects where nature-based solutions could reduce coastal flooding impacts. The highway corridor considered was State Route 1 from Dewey Beach to Fenwick. DelDOT also used the Guide as a reference for the development of their Strategic Implementation Plan for Climate Change, Sustainability, and Resilience for Transportation (23).

The SR 1 corridor is the main route along the coast from Fenwick Island, Delaware to Dewey Beach, Delaware and includes the towns of Bethany and South Bethany. The year-round populations in the towns are relatively small, but the summertime populations are significantly greater with tourists and seasonal residents going to the beaches. The four communities along the corridor are a significant contributor to Delaware's tourism industry. SR 1 is owned, operated, and maintained by the state, while surface streets in the towns are municipally maintained. The four cities are spread out along the corridor, with a state park separating Dewey Beach and Bethany and another state park separating South Bethany and Fenwick Island. Year-round (permanent) populations range from about 350 residents to 1000 whereas the summertime (tourist) population along the corridor can exceed 20000.

Table 4-1: Population Breakdown of Sussex County*, Delaware by Race. (Source: U.S. Census Bureau)

\begin{tabular}{|l|l|}
\hline White alone, percent & $82.7 \%$ \\
\hline Black or African American alone, percent & $12.5 \%$ \\
\hline American Indian and Alaska Native alone, percent & $1.1 \%$ \\
\hline Asian alone, percent & $1.3 \%$ \\
\hline Native Hawaiian and Other Pacific Islander alone, percent & $0.1 \%$ \\
\hline Two or More Races, percent & $2.1 \%$ \\
\hline Hispanic or Latino, percent & $9.4 \%$ \\
\hline White alone, not Hispanic or Latino, percent & $75.0 \%$ \\
\hline
\end{tabular}

Table 4-2: Income and Poverty Data for Sussex County*, Delaware. (Source: U.S. Census Bureau)

\begin{tabular}{|l|l|}
\hline Median household income (in 2016 dollars) (2012-2016) & $\$ 54218$ \\
\hline Per capita income in past 12 months (in 2016 dollars) 2012-2016) & $\$ 29630$ \\
\hline Persons in poverty, percent & $11.6 \%$ \\
\hline
\end{tabular}


* Note that data shown is for Sussex County, since the four cities along the SR 1 corridor have year-round populations of less than 5000 residents. Census data is only available for cities and towns with populations greater than 5000 .

\subsection{Major Hazards for State Route 1}

Delaware SR 1 is a coastal highway between Fenwick Island in the south and Dewey Beach to the north. There are only three east-west routes that intersect with SR 1: US 9 in the north, SR 26 at Bethany Beach and SR 54 at the southern end of the SR 1 corridor, making the corridor a critical transportation asset for the cities along the corridor. Much of the corridor crosses narrow strips of land with the Atlantic Ocean to the east and inland bays to the west. Due to the soil conditions, elevating the roadway is not possible in all locations, so SR1 is subject to flooding, usually from the bay side during nor'easters, tropical storms, and hurricanes when the winds tend to cause storm surge from the west. On the east, the highway is protected by dunes over much of its length, reducing the risk of flooding from the ocean side. 


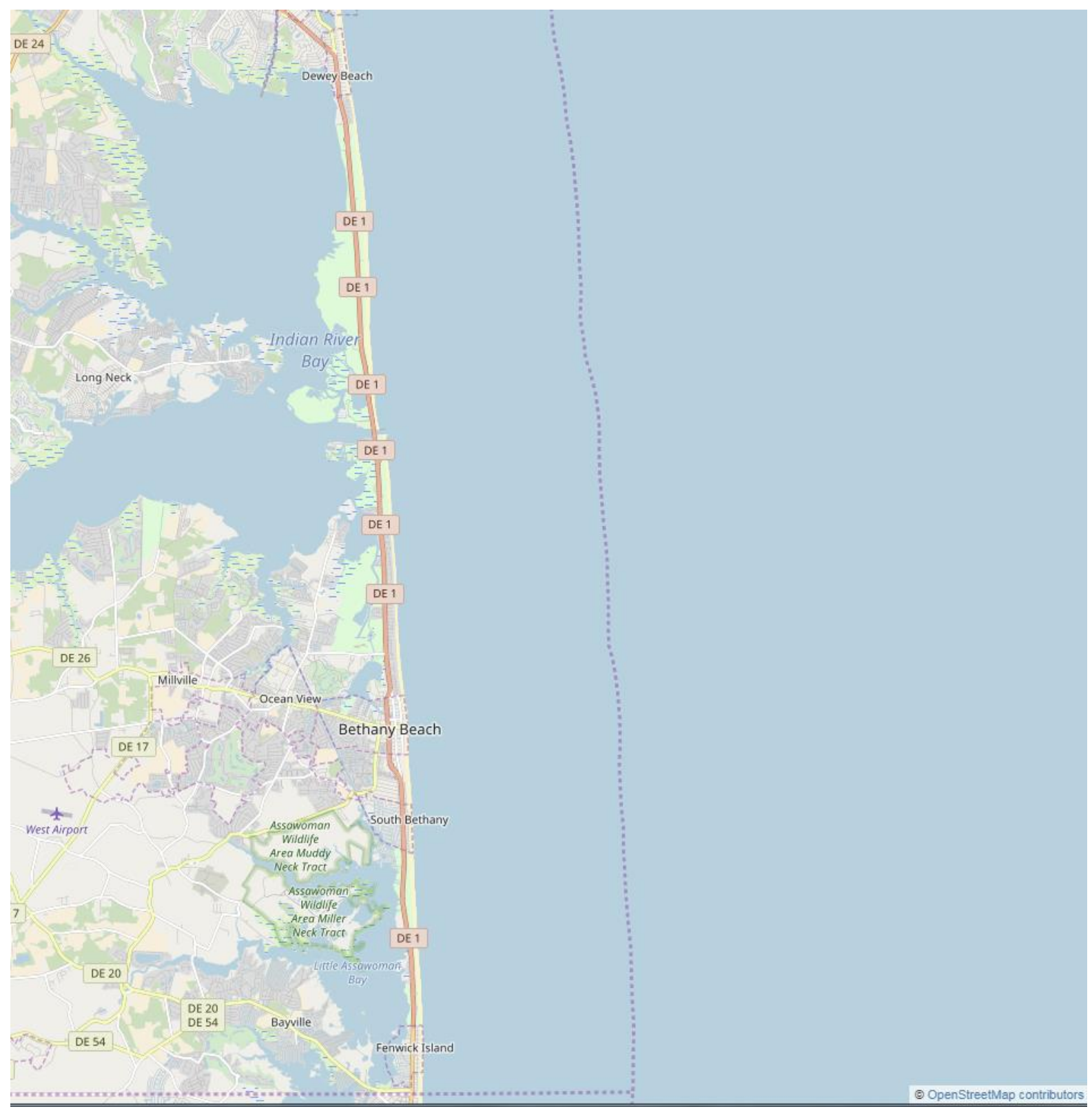

Figure 4-1: Delaware State Route 1 Corridor. (@OpenStreetMaps contributors).

\subsection{Current State of Planning in Community}

All the communities maintain and update master plans (reference). Sussex County maintains an up-to-date hazard mitigation plan (24) that includes the cities along the SR 1 corridor. DelDOT prepared a Strategic Implementation Plan for Climate Change, Sustainability, and Resilience for Transportation for all the state's transportation systems, including highway infrastructure. DelDOT conducts assessments of highway corridors to evaluate conditions, usage, and threats such as changes to environmental conditions that affect the corridor's availability. Since Delaware is a coastal state and there are projected changes in sea level rise and other climate factors that could impact the state's transportation, DelDOT addresses future conditions in its long-term planning. 


\subsection{Process Description}

The SR 1 corridor assessment was selected by DelDOT to address frequent flooding of the roadway in multiple locations. It was initially thought that sediment was impeding water drainage from the roadway. However, it was determined that sea level rise was the cause for more frequent flooding. The SR 1 study sought to develop an understanding of the problem and to identify solutions to reduce the frequency and severity of flooding, improving the resilience of the communities along the corridor.

Step 1: The CPT was led by a DelDOT engineer, supported by other DelDOT technical staff, The Delaware Center for the Inland Bays, and a contractor. The CPT engaged elected officials and staff in the four communities along the corridor to collect information on their priorities, dependencies on the corridor, and relevant plans.

Step 2: NIST met with the DelDOT team at their headquarters to review the two corridor assessments and the goals that DelDOT had for each assessment, the approach that would be taken to implement the Guide, and to discuss plans for a stakeholder meeting with the towns along the SR1 corridor.

The stakeholder meeting was an opportunity to introduce the Guide to officials in three of the four cities along the SR 1 corridor. Since DelDOT had worked with the cities previously, there was an existing relationship that allowed for the meeting to elicit information about the importance of the corridor. This discussion was facilitated by NIST and centered on Step 2 of the Guide, specifically characterizing the social and economic dimensions along the corridor and their dependencies on each other and the built environment. The discussion also touched briefly on Step 3 of the Guide by probing the types of hazards that the towns are most concerned about and the observed disruptions that result from those hazards. The five questions that were used for this discussion are the following:

- What are major social and economic functions (e.g., business, housing, etc.) along the Route 1 Corridor? How are these functions dependent on each other?

- How are these major social and economic functions dependent on buildings and infrastructure systems (e.g., power, water/wastewater, communications, transportation)? What infrastructure is most important in the community in the return of social and economic functions to 'normal'?

- How are the other infrastructure systems dependent on the Route 1 Corridor?

- When disruptions occur to the built infrastructure what is the extent of economic consequences? How are the social and economic consequences of interruptions linked to the recovery time?

- Are there other stakeholders who should be involved?

Each of the four cities have active planning efforts and all had up-to-date master plans or were in the process of updating their master plan. Further, Sussex County maintains an up-todate hazard mitigation plan that includes the four shore communities. 
Step 3: The facilitated meeting also provided information that assisted in understanding the community impacts that result when portions of the highway are inundated. The participants in the meeting described the role of the highway corridor in the region and the significant connection to the economic viability of the towns along the corridor. There was discussion of limitations on solutions that DelDOT faces given the location, soil conditions, and other factors.

The Guide provided the DelDOT team and local stakeholders a useful process for approaching the highway corridor assessment in terms of its role connecting the beach communities and as a right-of-way along which other infrastructure is located, and its importance to the local economy. The Guide supported a broader assessment of the consequences of flooding along the SR1 corridor. DelDOT and the cities along the SR 1 corridor did not complete the performance goals tables for Step 3 in the Guide process. However, the work that was performed using the Guide has led to the formation of a Resilience Council involving the cities and the county. The council is working to identify and address resilience issues that are common to the coastal cities. The Center for the Inland Bays continues to work on bioretention projects along the corridor to relieve flooding impacts due to coastal storms. DelDOT has identified specific projects including elevation of a section of the highway to further alleviate flood impacts. One of the issues that was brought up during the meeting with the cities was reliability of broadband service, which affected their ability to attract new businesses and could impact the ability to communicate with residents during an emergency. The collaboration of the cities enabled them to begin conversations with the broadband provider to improve the reliability of service to the cities.

Work on solutions to reduce the impact of flooding along the corridor is continuing. DelDOT plans to elevate a section of SR1. DelDOT is also working with the town of Dewey Beach to reduce flooding impacts. The Center for the Inland Bays had worked with the towns on storm water management and is now working on bioretention along the corridor to reduce the severity of floods.

\subsection{Assessment}

The SR 1 study used the Guide process to direct the corridor assessment, considering the dependencies of social and physical systems on the highway corridor. The Guide supported the formation of a collaboration of the four communities to more broadly work together to consider and address resilience concerns, including initiating discussions with the broadband service provider regarding reliability.

Step 1: Form a Collaborative Planning Team

A collaborative planning team supported by engagement of key stakeholders (officials from the four communities) supported the resilience assessment effort. A DelDOT team of engineers supports the corridor assessments and updates to the transportation strategic plan. For the SR 1 corridor, DelDOT worked with the Center for the Inland Bays and the local elected leadership and key senior permanent staff from three of the four towns along the corridor. An initial meeting was held with this group to facilitate a start to their planning 
process. While the Guide provided a useful framing for this and subsequent meetings between DelDOT, the four communities, and the Center for the Inland Bays.

Step 2: Understand the Situation

Resilience planning helped the participants to think more comprehensively about the importance of the highway corridor and dependencies on the highway and other infrastructure along the corridor. It also helped them to make connections between economic development or other objectives and the reliability of infrastructure during normal operation and during storm events. For example, the discussion with the cities, which focused on the transportation corridor, led to a broader discussion about infrastructure constraints to economic development (e.g., reliable broadband internet access).

Step 3: Determine Goals and Objectives

The DelDOT application of the Guide for a highway corridor assessment was a useful test of the Guide's flexibility. While the process was useful to elicit information from the affected communities that informed the highway corridor assessment, the time and budget constraints of such a study proved a challenge to fully implement a resilience plan for the corridor, gradually building resilience as capital projects are undertaken. However, the resilience council that did result from the engagement of the four cities may lead to further resilience building efforts in the future.

There has been an effort by the four communities to engage with the broadband provider to reduce the frequency of outages due to storms. More reliable broadband internet service was noted by the local government representatives as important to attracting businesses to the region.

Greater participation in the initial meeting with the towns would have been desirable. This might have led to greater engagement and closer adherence to the Guide process. 


\section{Summary}

These examples of Guide use highlight some of the features of the process that NIST believes will help communities increase their resilience to hazards by considering the dependencies. It also, however, points to some gaps that NIST is working to address. The range of applications, use of the Guide, and lessons for future guidance and tools are summarized below.

\subsection{Range of Applications}

The three case studies described demonstrate the applicability of the Guide process in different settings. The Fort Collins and Howard County examples demonstrate application for a municipality and a district (within a County). The DelDOT highway corridor case study shows how the process can be applied over a region and in this case with a central infrastructure asset being the focus of the assessment and considering its role in the context of the communities along the corridor.

\subsection{Use of the Guide}

One of the strengths identified in these implementations was that the Guide process provides a means for bringing together the diverse set of stakeholders to establish a shared set of resilience goals for the community. Engagement of stakeholders to communicate the value of resilience planning, elicit information on dependencies on services, buildings, and infrastructure is essential to accurately characterizing the community and appropriately assigning performance goals.

The concept of integrating resilience into other community-level plans came up in all three implementations. A community resilience plan should identify actions that can be implemented through the community's master plan or hazard mitigation plan. The implementations provided valuable insights into how the Guide should work in concert with other plans. The Fort Collins implementation illustrates this well: the city has an active planning process, so the team saw little value in developing another plan. Rather, the CPT developed a set of recommendations, based on resilience goals and performance gaps, that could be implemented through the appropriate existing plan.

Howard County is taking measures to integrate their planning processes to make sure that all plans are aligned to the same set of resilience goals and objectives.

Use of the performance goal tables (Step 3) demonstrated the value of obtaining a high-level perspective on the community and where performance gaps exist. Identifying these gaps enables the user to prioritize the gaps and evaluate alternative solutions. Use of the tables also helps the collaborative planning team identify where dependency relationships can lead to unintended performance gaps. The tables are also useful for tracking progress toward improving resilience over time. 


\subsection{Lessons for Future Guidance and Tools}

Geospatial data showing where buildings or infrastructure are likely to be damaged and the resulting impacts on social and economic activity can be particularly useful for determining anticipated performance, identifying possible solutions to address performance gaps, and establishing priorities. The Fort Collins implementation demonstrated the value of using geospatial data to inform the resilience analysis.

Estimating anticipated performance for the built environment is an area that requires additional development. There are currently no tools that work specifically with the Guide process to estimate anticipated performance. This is currently accomplished through expert judgement. A dependency mapping tool was applied effectively in the Fort Collins work. Automating dependency mapping and determination of anticipated performance will make the process more accessible to users and would support broader application of the Guide for resilience planning.

Each community developed its own interpretation of how to use the Guide. In only one case were the performance goal tables used and in that case the tables were modified to suit the assessment, although the basic principles articulated by the Guide were followed. The Guide process is most useful in obtaining a system level view of the community so that dependencies and cascading consequences can identified.

These implementations demonstrate value in the Guide process but also identified additional guidance and tools that are needed to support a broader implementation of the Guide process:

- Building cluster mapping - The building clusters represent buildings that contribute to the provision of a social service (e.g., housing, critical retail, education). Automating the identification of which buildings in a community belong to a cluster would greatly simplify the population of the performance goals tables and assist communities in establishing their desired performance for each cluster.

- Dependency mapping - tools to automate the analysis of dependencies and the cascading consequences of failures would simplify the determination of anticipated performance.

- Tools to estimate anticipated performance - tools that can assist the user in determining anticipated performance would simplify this part of the resilience planning process. Such tools would need to include not only damage assessment, but recovery of function. Along with dependency mapping, this will help the user estimate anticipated performance.

- Training on the use of the Guide - A workbook that takes a user step by step through how to implement the Guide process and points to existing tools that can support the resilience planning process will make the planning process more uniform and lead to more consistent outcomes. 


\section{References}

1. Community Resilience Planning Guide for Buildings and Infrastructure Systems, Volume 1, NIST Special Publication 1190, May 2016, https://nvlpubs.nist.gov/nistpubs/SpecialPublications/NIST.SP.1190v1.pdf.

2. Community Resilience Planning Guide for Buildings and Infrastructure Systems, Volume 2, NIST Special Publication 1190, May 2016, https://nvlpubs.nist.gov/nistpubs/SpecialPublications/NIST.SP.1190v2.pdf.

3. Gilbert, S.W., Butry, D.T., Helgeson, J.F., Chapman, R.E., Community Resilience Economic Decision Guide for Buildings and Infrastructure Systems, NIST Special Publication 1197, December 2015, https://nvlpubs.nist.gov/nistpubs/SpecialPublications/NIST.SP.1197.pdf.

4. The Resilient City: Defining What San Francisco Needs from its Seismic Mitigation Policies, Poland, C.D., et al., February 2009, https://www.spur.org/sites/default/files/publications_pdfs/SPUR_Seismic_Mitigation Policies.pdf.

5. The Oregon Resilience Plan: Reducing Risk and Improving Recovery for the Next Cascadia Earthquake and Tsunami, Oregon Seismic Safety Policy Advisory Committee, February 2013, https://www.oregon.gov/oem/Documents/Oregon_Resilience_Plan_Final.pdf.

6. Colorado Resilience Framework, May 2015, https://docs.google.com/a/state.co.us/viewer?a=v\&pid=sites\&srcid=c3RhdGUuY28u dXN8Y29sb3JhZG91bml0ZWR8Z3g6MmRmMjlmMjMwOTBlMjNkYw.

7. United States Department of Homeland Security Regional Resilience Assessment Program, https://www.dhs.gov/regional-resiliency-assessment-program.

8. Fort Collins, Colorado, Wikipedia, https://en.wikipedia.org/wiki/Fort_Collins,_Colorado

9. City of Fort Collins Strategic Plan, https://ourcity.fcgov.com/update-the-citys-2018strategic-plan.

10. City of Fort Collins City Plan, https://ourcity.fcgov.com/update-the-citys-2018strategic-plan.

11. Adopted Plans for the City of Fort Collins, https://www.fcgov.com/planfortcollins/.

12. Northern Colorado Hazard Mitigation Plan, http://mitigationguide.org/wpcontent/uploads/2013/05/Northern-Colorado-Hazard-Mitigation-Plan-Final.pdf. 
13. Fort Collins Government Utilities, https://www.fcgov.com/utilities/what-wedo/stormwater/flooding/.

14. Fort Collins Government Utilities, 2013 Flood, https://www.fcgov.com/utilities/whatwe-do/stormwater/flooding/.

15. Howard County, Maryland, Wikipedia, https://en.wikipedia.org/wiki/Howard_County,_Maryland

16. Plan Howard 2030, https://www.howardcountymd.gov/LinkClick.aspx?fileticket=A2GBRU1ww2U\%3d $\underline{\text { \&portalid }=0 \text {. }}$

17. Howard Count Emergency Management Plan, https://www.howardcountymd.gov/LinkClick.aspx?fileticket=hFtI8lld_Qc\%3d\&porta $\underline{\text { lid}=0}$.

18. Howard County Economic Development Plan, http://www.hceda.org/wpcontent/uploads/2017-HCEDA-Strategic-Plan.pdf.

19. Howard County General Plan, https://www.howardcountymd.gov/Departments/Planning-and-Zoning/CommunityPlanning/General-Plan.

20. State of Maryland Hazard Mitigation Plan, https://mema.maryland.gov/community/Documents/2016\%20Maryland\%20Hazard\% 20Mitigation\%20Plan\%20final\%202.pdf.

21. Clinch, R., The Economic Impact of the 2016 Ellicott City Flood, University of Baltimore, Jacob France Institute, 2016, http://www.jacob-france-institute.org/wpcontent/uploads/Economic-Impact-Ellicott-City-Flood-2016.pdf.

22. Howard County Maryland, Ellicott City Flood Recovery, https://www.howardcountymd.gov/Departments/Ellicott-City-2016-Flood-Recovery.

23. Delaware Strategic Implementation Plan for Climate Change, Sustainability, and Resilience for Transportation, https://deldot.gov/Publications/reports/SIP/pdfs/SIP_FINAL_2017-07-28.pdf.

24. Sussex County, Delaware Hazard Mitigation Plan, https://sussexcountyde.gov/sites/default/files/PDFs/SussexCounty_2016_HMP_Upda te.pdf.

25. United States Census Bureau, Population and Housing Unit Estimates, https://www.census.gov/programs-surveys/popest/data/data-sets.html. 


\section{Appendix A: Sample Stakeholder Questionnaires}

The Fort Collins collaborative planning team developed two questionnaires to collect information from stakeholder groups. The first was intended for use by stakeholder groups representing one of the eight social dimensions in the community as identified in the Guide, in the example, Family \& Kinship (p. 27 of Volume 2 of the Guide). This social dimension can be mapped onto building clusters, in this example housing, that support the activity within the social dimension. These questionnaires were used in a workshop setting with breakout groups discussing responses to the questions. The references to "table" are instructions to the breakout groups.

A separate questionnaire was developed for use in guiding discussions with infrastructure operators. Responses to the questions provided useful insights to the individual infrastructure systems and helped the collaborative planning team refine the analyses that they were conducting using open source information.

Both questionnaires are provided here. 


\section{Example Social Dimensions Task Worksheet \& Questions \\ Family \& Kinship}

1) Please review the "one pager" of functions/services to the community provided by your social function category.

$>$ Is it complete? If not, what's missing?

$>$ Should anything be deleted?

Please make additions or deletions to the Master Sheet (corresponding to Question 1) provided to your table.

2) List the 1-2-3 most important functions/services that your social function category provides to the community:

1.

2.

3.

Please list consensus selections on the Master Sheet (corresponding to Question 2) provided to your table.

3) Indicate which elements of the built environment are necessary to support the provision of the important functions/services listed in question 2? (Include only physical assets, e.g., specific buildings, gathering places, emergency vehicles, etc., or other like assets. Do not include lifeline infrastructure - power, water, wastewater, communications, and transportation systems - that support the provision of these services.)

1.

2.

3.

Please list consensus selections on the Master Sheet (corresponding to Question 3) provided to your table. 
4) Following a disruptive event that impacts lifeline sector services to the built environment (e.g., water or energy to a hospital; delivery of food and supplies to a food bank; communications services to a fire department or 911 call center), what are your recovery goals for the three critical functions/services listed in response to question 2 ?

1.

2.

3.

Please list consensus selections on the Master Sheet (corresponding to Question 4) provided to your table.

5) What steps have been taken to mitigate the impacts of disruptive events on the critical assets listed in response to question 3?

Please list consensus selections on the Master Sheet (corresponding to Question 5) provided to your table.

6) Please review the list of assets linked to your social function category:

Are these facilities properly allocated to the social function category? If so, briefly discuss what role they play under steady state conditions, during a disaster or post disaster. If not, please indicate which assets are misallocated.

$>$ Are important assets missing? If so, please list them on the spreadsheet provided.

$>$ If possible, please rank the importance of the listed assets to your social function category using the following key:

$\checkmark \quad 1$ (Critical to delivery of essential function provided by this social function category - loss of this asset would result in inability to provide a critical social need. There are no available substitutes for the services/functions provided by this asset)

$\checkmark 2$ (Important to delivery of essential function provided by this social function category - loss of this asset would result in diminished capacity to provide a critical social need. There are few readily available substitutes for the services/functions provided by this asset)

$\checkmark \quad 3$ (Non-essential to delivery of essential functions/services provided by this social function category - loss of this asset would not result in diminished capacity to provide a critical social need. There are readily available substitutes for the services/functions provided by this asset) 
Please list consensus selections on the Master Sheet (corresponding to Question 6) provided to your table.

7) Please provide the group's thoughts and recommendations on how we can best insure that this specific social function group is successfully integrated into the Community Resilience Planning process.

Please list your recommendations on the Master Sheet (corresponding to Question 7) provided to your table. 


\section{Example Questions for Infrastructure Owner/Operator}

1) What are the factors you don't control that affect your sector or facility's ability to remain operational and perform mission essential functions during or following a disruptive event, e.g., dependencies on other lifeline sectors (power, water, communications, etc.), dependencies on government (road/debris clearing, permitting, regulatory waivers)?

2) Do recovery time objectives (rto's) in your business continuity plan factor in the recovery capabilities of the external entities you depend on?

3) In Northern Colorado, what are the barriers to meeting specific rtos?

4) Do State, County and local emergency managers know what you do and prioritize and facilitate restoration of the services your facility provides? Do they understand your requirements and the consequences of loss of functionality?

5) You provide essential lifeline functions. Have you had discussions with emergency managers and County and local decision-makers about their restoration priorities? Do you factor their priorities into your plans?

6) Have you taken steps to mitigate consequences of a service interruption? (back-up power, priority fuel contracts, WPS/GETS, dual electrical feeds to critical assets, etc.)

7) Do emergency managers and the service providers you depend on know your capacity to remain operational following the loss of a critical service? 